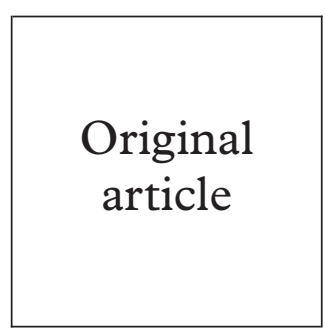

\title{
Epidemiology of vulvar vestibulitis syndrome: an exploratory case-control study
}

\author{
A V Sarma, B Foxman, B Bayirli, H Haefner, J D Sobel
}

Background: Vulvar vestibulitis syndrome (VVS) is a chronic, persistent syndrome characterised by vestibular pain, tenderness, and erythema. The aetiology of VVS is unknown and few of the hypothesised risk factors have been tested in controlled studies.

Methods: Using a matched case-control study design, medical, sexual, health behaviour, and diet history of 28 women with VVS were compared with 50 friend controls without VVS to identify possible causal factors.

Results: Cases were more likely than controls to report every vaginal and urinary symptom at the time of interview measured, particularly vaginal soreness or pain $(60.7 \%)$ and pain during intercourse $(64.3 \%)$. There were no significant differences between cases and controls with respect to sexual behaviour. Cases were more likely than controls to report self reported history of physician diagnosed bacterial vaginosis $(\mathrm{OR}=22.2,95 \% \mathrm{CI}=2.8,177.2, \mathrm{p}$ value $=0.0001)$, vaginal yeast infections $(\mathrm{OR}=4.9,95 \% \mathrm{CI}=1.4,18.0, \mathrm{p}$ value $=0.01)$, and human papillomavirus $(\mathrm{OR}=7.1$, $95 \% \mathrm{CI}=0.6,81.2, \mathrm{p}$ value $=0.08)$. There were no differences between cases and controls with respect to dietary intake of oxalate. Cases were more likely than controls to report poor health status $(\mathrm{OR}=5.7,95 \% \mathrm{CI}=1.1,28.7$, $\mathrm{p}$ value $=0.02)$ and history of depression for 2 weeks or more during the past year $(\mathrm{OR}=4.4,95 \% \mathrm{CI}=1.6,12.3$, $\mathrm{p}$ value $=0.002)$.

Conclusion: Self reported history of bacterial vaginosis, yeast infections, and human papillomavirus were strongly associated with VVS. An infectious origin for VVS should be pursued in larger controlled studies, using questionnaire and laboratory measures.

(Sex Transm Inf 1999;75:320-326)

Keywords: vulvar vestibulitis syndrome; vulvar pain; risk factors

\section{Introduction}

Vulvar vestibulitis syndrome (VVS) is a chronic, persistent clinical syndrome characterised by a constellation of signs and symptoms that involve the vulvar vestibule. The prevalence of VVS in a general gynaecological practice has been estimated to be as much as $15 \% .{ }^{1}$ The aetiology of VVS is unknown, and the causes are most probably multifactorial. ${ }^{1}$ Histopathological studies of sensitive vestibular tissue consistently reveal non-specific chronic inflammatory changes often with prominence of mast cells. ${ }^{2}$ Very little epidemiological information characterising risk factors for this syndrome is available.

There are various theories regarding VVS aetiology. A common theme is that an environmental factor has sensitised the nerve endings of the vestibule. Studies of nerve injury due to disease have focused primarily on history of candidal infection ${ }^{3-7}$ and HPV, ${ }^{45-12}$ but have found contradictory results. Associations of VVS with allergies, ${ }^{4} 7_{13}^{13}$ hormonal factors, ${ }^{15} 1214$ and urethral conditions $\mathrm{s}^{15-19}$ have been hypothesised and tested with results being contradictory. Although iatrogenic factors, immune function, and sympathetically maintained pain have also been hypothesised to cause VVS, there are no studies either to support or refute these hypotheses. ${ }^{1}$ Sexual behaviour, psychological factors, and general health behaviours are also hypothesised to be associated with VVS but empirical data are scarce and only two studies have examined these associations. ${ }^{3}{ }^{18}$
The symptoms of burning, itching, and pain associated with VVS resemble very closely those symptoms of a disorder which results in an accumulation of crystals of calcium oxalate in various anatomical sites. ${ }^{20}$ In a case report of a patient who suffered from VVS, it was found that excessive amounts of calcium oxalate existed in the patient's urine sample. ${ }^{20} \mathrm{~A}$ case-control study of 130 patients with vulvar pain syndrome and 23 volunteers without symptoms, however, found no significant differences in urinary oxalate excretion. ${ }^{21}$ We are unaware of other studies examining the association of calcium oxalate and/or diet with VVS.

\section{Methods}

We conducted an exploratory case-control study of women with VVS and matched friend controls to address several hypotheses postulated to be involved in the aetiology of VVS using a controlled epidemiological design.

\section{CASE AND CONTROL DEFINITIONS}

Cases were eligible to participate if they had VVS diagnosed within 6 months before the time identified for study. VVS was defined as: (1) vulvovaginal pain, burning, soreness, or irritation, (2) penetration dyspareunia, (3) erythema localised to the vestibule which may be focal, bilateral, or diffuse, and (4) severe pain or tenderness on vestibular touch elicited by a cotton tipped applicator. ${ }^{13}$ Other causes of vestibulitis were excluded. Cases were those newly diagnosed with VVS at the study site or previously diagnosed at some other site and referred 
for treatment at the site. Controls were defined as women without VVS. Self report of VVS was deemed sufficient to exclude women from the control group.

\section{STUDY PROTOCOL}

Cases were recruited primarily from three Ann Arbor/Detroit area gynaecological clinics: (1) The University of Michigan Center for Vulvar Diseases $(n=16),(2)$ Wayne State University Vaginitis Clinic ( $n=19)$, and (3) Dr Richard Reid's private practice $(n=28)$. One case was recruited from another private practice. The participating clinics provided us with the names and phone numbers of women who were referred with VVS meeting the study definition between 1 May 1995 and 1 July 1997. At the University of Michigan Center for Vulvar Diseases and Dr Reid's private practice, women who were scheduled for an appointment for complaints of VVS symptoms were contacted by mail a few days after their appointment to request participation in the study. The women were mailed a study packet which included a contact letter describing the study, a consent form to abstract the patient's medical record, a self administered diet questionnaire, and a stamped, addressed envelope for return upon completion. Once written consent was received, medical records were reviewed by study personnel to verify the diagnosis met the study case definition. Verbal consent was obtained to conduct the telephone interview. Wayne State University Vaginitis Clinic provided us with a list of patients newly diagnosed with VVS according to the study definition. These patients were contacted by mail and telephone in the manner described above. At the University of Michigan Center for Vulvar Diseases and Wayne State University Vaginitis Clinic, patients were contacted within a month after verification of diagnosis. At Dr Reid's clinic, patients were contacted up to 6 months after diagnosis.

Upon completion of the interview, cases were asked for the names of five friends and/or neighbours approximately the same age who had not been diagnosed with VVS. Cases were instructed to rank the individuals from 1 to 5 , in order of whom they "felt closest to." Addresses and phone numbers of the people were also requested. Those individuals ranked first were contacted to complete the study. If this individual refused or could not be found, the individual ranked second was contacted, etc. At least one control per case was enrolled in the study for 28 of the 64 cases. This study was approved by the University of Michigan Medical Center, University of Michigan School of Public Health, and Wayne State University institutional review boards.

MEASURING INSTRUMENTS

All subjects participated in a 15 minute questionnaire administered over the telephone. The questionnaire had the following components: "Introduction and recruitment," "Urinary and vaginal symptoms," "Menstrual history," "Oestrogen replacement history," "Medication history," "Allergy history," "Sexu- ally transmitted diseases," "Sexual behaviour," "Contraceptives," "General health," "Psychological history," and "Sociodemographics."

A separate self administered diet questionnaire (sent with the study packet) allowed us to determine dietary oxalate intake. The diet questionnaire was developed from a patient oxalate meal plan. ${ }^{22}$ We asked participants to indicate the number of times specific foods or beverages had been taken during the past 4 weeks. The questionnaire included foods under the following eight categories: beverages, meats, dairy, fats and oils, fruits, vegetables, breads/starches, and miscellaneous. Each item was ranked as high, medium, or low in oxalate level. Total units of intake were calculated for each of the oxalate level categories.

\section{STATISTICAL METHODS}

We described the distribution of risk factors associated with VVS for both cases and controls using simple descriptive statistics. Differences in distribution of these variables were tested using the matched paired $t$ test for continuous variables and the matched $\chi^{2}$ test for association for categorical variables with a two tailed significance level of 0.05 . Because we did multiple comparisons, we also calculated the significance using a Bonferroni type correction for the matched $\chi^{2}$ tests. $^{23}$ Associations that remained significant following correction are noted in tables 1-4. Conditional logistic regression was used to calculate matched odds ratios and their $95 \%$ confidence intervals (CI) to determine the significance of the association. Logit estimates of the matched odds ratios and their $95 \%$ confidence intervals were used when matched cell sizes were zero. Analysis was done using SAS for Windows $6.10 .^{24}$

\section{Results}

A total of 125 women were initially identified as having VVS. Six women were excluded after medical record review indicated that they did not meet the study definition of VVS. We were unable to contact 35 women for participation owing to an incorrect phone number or address or no answer in 10 attempts to contact. Of the 84 women contacted, 20 refused to participate in the study giving us a response rate of $76.2 \%$ for the cases. Of the 64 cases who participated in the study, $28(43.8 \%)$ provided us with names of friends to contact as potential controls. A total of 104 potential friend controls were identified; one woman had been diagnosed with VVS previously and thus was excluded. Thirty nine of the potential friend controls were unable to be reached owing to an incorrect phone number, or address, or no answer. Of the 64 women contacted, 50 (80.6)\% participated in the study. There were no statistically significant differences with respect to most of the studied characteristics among cases who provided us with names of friend controls (matched cases) compared with those cases who did not provide us with names of friends (unmatched cases). 
Table 1 Demographic characteristics and current vaginal and urinary symptoms among 64 women with vulvar vestibulitis syndrome and 50 matched friend controls

\begin{tabular}{|c|c|c|c|c|c|}
\hline \multirow[b]{2}{*}{ Demographic characteristics } & $\begin{array}{l}\text { Unmatched cases } \\
(n=36)\end{array}$ & $\begin{array}{l}\text { Matched cases } \\
(n=28)\end{array}$ & $\begin{array}{l}\text { Friend controls } \\
(n=50)\end{array}$ & \multirow{2}{*}{$\begin{array}{l}\text { Matched } \\
\chi^{2} p \text { value }\end{array}$} & \multirow{2}{*}{$\begin{array}{l}\text { Matched OR } \\
(95 \% \mathrm{CI})\end{array}$} \\
\hline & No $(\%)$ & No $(\%)$ & No $(\%)$ & & \\
\hline \multicolumn{6}{|l|}{ Age } \\
\hline $18-34$ & $18(50.0)$ & $18(64.3)$ & $21(42.0)$ & \multirow[t]{2}{*}{0.01} & \multirow[t]{2}{*}{$0.2(0.1,1.0)^{\star}$} \\
\hline 35 and older & $18(50.0)$ & $10(35.7)$ & $29(58.0)$ & & \\
\hline \multicolumn{6}{|l|}{ Race } \\
\hline White & $35(91.2)$ & $28(100.0)$ & $48(96.0)$ & \multirow[t]{2}{*}{0.3} & \multirow{2}{*}{$0.2(.01,8.8)^{\star}$} \\
\hline Non-white & $1(2.8)$ & $0(0.0)$ & $2(4.0)$ & & \\
\hline \multicolumn{6}{|l|}{ Marital status } \\
\hline Married & $27(75.0)$ & $19(67.9)$ & $31(62.0)$ & \multirow[t]{2}{*}{0.3} & \multirow[t]{2}{*}{$0.5(0.1,2.0)$} \\
\hline Not married & $9(25.0)$ & $9(32.1)$ & $19(38.0)$ & & \\
\hline \multicolumn{6}{|l|}{ Education } \\
\hline High school & $7(19.4)$ & $4(14.3)$ & $11(22.0)$ & \multirow[t]{2}{*}{0.2} & \multirow[t]{2}{*}{$2.9(0.6,14.8)$} \\
\hline$>$ High school & $29(80.6)$ & $24(85.7)$ & $39(78.0)$ & & \\
\hline \multicolumn{6}{|l|}{ Vaginal symptoms } \\
\hline Itching & $11(30.6)$ & $11(39.3)$ & $3(6.0)$ & $0.001 \ddagger$ & $9.6(2.1,44.7)$ \\
\hline Discharge & $11(30.6)$ & $12(42.9)$ & $9(18.0)$ & 0.02 & $4.0(1.1,15.0)$ \\
\hline Odour & $6(16.7)$ & $8(28.6)$ & $4(8.0)$ & 0.01 & $4.1(1.3,19.5)$ \\
\hline Burning during urination & $5(13.9)$ & $12(42.9)$ & $2(4.0)$ & $0.001 \ddagger$ & $14.0(1.8,109.8)$ \\
\hline Soreness or pain & $23(63.9)$ & $17(60.7)$ & $2(4.0)$ & $0.0001 \ddagger$ & $9.4(3.3,27.3)^{\star}$ \\
\hline Pain during vaginal intercourse & $16(44.4)$ & $18(64.3)$ & $1(2.0)$ & $0.0001 \ddagger$ & $10.5(3.7,29.9)^{\star}$ \\
\hline Other & $4(11.1)$ & $2(7.1)$ & $1(2.0)$ & 0.2 & $4.6(0.4,57.2)$ \\
\hline \multicolumn{6}{|l|}{ Urinary symptoms } \\
\hline Urination more frequent than usual & $4(11.1)$ & $8(28.6)$ & $6(12.0)$ & 0.1 & $2.4(0.8,7.6)$ \\
\hline Painful urination & $6(16.7)$ & $7(25.0)$ & $1(2.0)$ & 0.01 & $8.4(1.6,44.1)^{\star}$ \\
\hline Urination at night & $4(11.1)$ & $8(28.6)$ & $3(6.0)$ & 0.01 & $6.1(1.3,29.6)$ \\
\hline An urgent need to urinate & $9(25.0)$ & $10(35.7)$ & $1(2.0)$ & $0.001 \ddagger$ & $15.1(1.9,120.5)$ \\
\hline Pain or pressure in lower abdomen & $11(30.6)$ & $11(39.3)$ & $3(6.0)$ & 0.01 & $5.1(1.4,19.0)$ \\
\hline Blood in urine & $1(2.8)$ & $3(10.7)$ & $3(6.0)$ & 0.3 & $2.2(0.4,11.9)$ \\
\hline Other & $1(2.8)$ & $2(7.1)$ & $1(2.0)$ & 0.3 & $3.4(0.3,42.3)$ \\
\hline
\end{tabular}

${ }^{\star}$ Logit estimates for the matched OR and $95 \% \mathrm{CI}$ were calculated if any of the matched cells were 0 .

† Matched OR and $95 \% \mathrm{CI}$ were not calculated if any of the unmatched cells were 0 .

$\ddagger$ Statistically significant $(\mathrm{p}<0.05)$ with Bonferroni type correction.

\section{DEMOGRAPHICS}

Cases were slightly younger than matched controls $($ mean $=33.4 v 37.2$, $\mathrm{p}$ value $=0.03)$. However, cases and controls were similar with respect to race, marital status, and education (table 1).

\section{SYMPTOMS}

Cases were more likely than controls to report every vaginal and urinary symptom at the time of the interview (table 1). The most frequently reported vaginal symptoms among matched cases were vaginal soreness or pain (60.7\%) and pain during intercourse (64.3\%). By contrast, the most common vaginal symptom among controls was vaginal discharge (18.0\%). Cases with matched controls reported higher rates of most vaginal and urinary symptoms compared with unmatched cases. In particular, cases with matched controls reported higher rates of burning during urination compared with unmatched cases $(42.9 \%$ v $13.9 \%$, p value $=0.009)$.

\section{SEXUAL ACTIVITY}

All cases (100.0\%) and almost all controls (98.0\%) reported ever being sexually active (table 2). Age at first sexual activity was not significantly different among cases and controls; the average age at coitarche for both groups was 18.5 years ( $\mathrm{p}$ value $=0.9$ ). Additionally, both cases and controls averaged four sex partners in their life ( $p$ value $=0.8$ ). Cases without controls compared with matched cases were more likely to report five or more sex partners in their life $(36.1 \% v 14.3 \%, \mathrm{p}$ value $=0.05)$. With respect to current sexual activity, sexual activity within the past 12 months and specific sexual activities, there were no significant differences between matched cases and controls (table 2). However, matched cases were significantly more likely than unmatched cases to report sex in the past 12 months $(100 \%$ v $80.6 \%$, p value $=0.01)$. While cases were somewhat less likely than matched controls to report oral sex $(\mathrm{OR}=0.5$, $95 \% \mathrm{CI}=0.2,1.4, \mathrm{p}$ value $=0.2)$, both cases and controls reported engaging in vaginal intercourse on a regular basis $(\mathrm{OR}=1.3 ; 95 \%$ $\mathrm{CI}=0.4,4.2)$.

MEDICAL HISTORY AND HEALTH BEHAVIOUR

Cases were twice as likely as matched controls to report a history of allergies $(\mathrm{OR}=2.3$, $95 \% \mathrm{CI}=0.8,6.6, \mathrm{p}$ value $=0.1)$ and three times more likely than matched controls to be under a doctor's care for their allergies $(\mathrm{OR}=3.2$, $95 \% \mathrm{CI}=0.6,16.7, \mathrm{p}$ value $=0.1)$ but the results were not statistically significant. Cases were six times more likely than matched controls to report use of vaginal preparations such as creams, suppositories, anti-itching preparations, or antifungals with or without a prescription $(\mathrm{OR}=6.7,95 \% \mathrm{CI}=1.4,32.5, \mathrm{p}$ value $=0.007)$. Cases and matched controls were equally likely to use vaginal moisturisers $(\mathrm{OR}=1.4 ; 95 \% \mathrm{CI}: 0.3,6.3)$ and hygiene products $(\mathrm{OR}=0.7,95 \% \mathrm{CI}=0.1,4.1, \mathrm{p}$ value $=0.7)$. Cases $(42.1 \%)$ were less likely than matched controls $(50.0 \%)$ to report use of tampons $(\mathrm{OR}=0.4,95 \% \mathrm{CI}=0.1,1.5, \mathrm{p}$ value $=0.2)$ and more likely than matched controls to report use of sanitary napkins $(94.7 \%$ cases $v 73.1 \%$ matched controls). Although cases were more likely than matched controls to report using a product containing oestrogen $(\mathrm{OR}=5.3$, 
Table 2 Sexual behaviour characteristics among 64 women with vulvar vestibulitis syndrome and 50 matched friend controls

\begin{tabular}{|c|c|c|c|c|c|}
\hline \multirow[b]{2}{*}{ Sexual behaviour characteristics } & \multirow{2}{*}{$\begin{array}{l}\begin{array}{l}\text { Unmatched cases } \\
(n=36)\end{array} \\
\text { No }(\%)\end{array}$} & \multirow{2}{*}{$\begin{array}{l}\begin{array}{l}\text { Matched cases } \\
(n=28)\end{array} \\
\text { No (\%) }\end{array}$} & \multirow{2}{*}{$\begin{array}{l}\text { Friend controls } \\
(n=50)\end{array}$} & \multirow{2}{*}{$\begin{array}{l}\text { Matched } \chi^{2} \\
\text { p value }\end{array}$} & \multirow{2}{*}{$\begin{array}{l}\text { Matched OR } \\
(95 \% \text { CI) }\end{array}$} \\
\hline & & & & & \\
\hline Ever engaged in sexual activity & $36(100.0)$ & $28(100.0)$ & $48(98.0)$ & 0.6 & $1.8(0.04,79.4)^{\star}$ \\
\hline \multicolumn{6}{|l|}{ Age at first sexual activity } \\
\hline$<18$ & $13(36.1)$ & $11(39.3)$ & $15(31.3)$ & \multirow[t]{2}{*}{0.5} & \multirow[t]{2}{*}{$0.7(0.2,2.0)$} \\
\hline 18 or more & $23(63.9)$ & $17(60.7)$ & $33(68.7)$ & & \\
\hline \multicolumn{6}{|l|}{ Lifetime number of partners } \\
\hline$<5$ & $23(63.9)$ & $24(85.7)$ & $30(63.8)$ & \multirow[t]{2}{*}{0.07} & \multirow[t]{2}{*}{$0.3(0.1,1.1)$} \\
\hline 5 or more & $13(36.1)$ & $4(14.3)$ & $17(36.2)$ & & \\
\hline Sex in the past 12 months & $29(80.6)$ & $28(100.0)$ & $42(89.4)$ & 0.1 & $4.2(0.6,32.3)^{\star}$ \\
\hline \multicolumn{6}{|c|}{ Number of times engaged in sex in a typical month in past 12 months } \\
\hline$<5$ & $18(62.1)$ & $17(60.7)$ & $21(50.0)$ & \multirow[t]{2}{*}{0.4} & \multirow[t]{2}{*}{$0.6(0.2,1.9)$} \\
\hline 5 or more & $11(37.9)$ & $11(39.3)$ & $21(50.0)$ & & \\
\hline \multicolumn{6}{|l|}{ Time of last sexual activity } \\
\hline$<2$ years & $34(94.4)$ & $27(96.4)$ & $45(91.8)$ & \multirow[t]{2}{*}{0.5} & \multirow[t]{2}{*}{$0.5(0.1,5.0)$} \\
\hline 2 years or more & $2(5.6)$ & $1(3.6)$ & $4(8.2)$ & & \\
\hline Receptive genital stimulation in the & & & & & \\
\hline $\begin{array}{l}\text { past } 4 \text { weers } \\
\text { Receptive oral sex in the past } 4 \text { weeks }\end{array}$ & $\begin{array}{l}20(58.8) \\
12(38.7)\end{array}$ & $\begin{array}{r}20(74.1) \\
9(34.6)\end{array}$ & $\begin{array}{l}32(72.7) \\
21(51.2)\end{array}$ & $\begin{array}{l}0.4 \\
0.2\end{array}$ & $\begin{array}{l}1.9(0.5,7.5) \\
0.5(0.2,1.4)\end{array}$ \\
\hline Vaginal intercourse in the past 4 weeks & $20(57.1)$ & $18(69.2)$ & $31(68.9)$ & 0.6 & $1.3(0.4,4.2)$ \\
\hline
\end{tabular}

$\star$ Logit estimates for the matched OR and $95 \% \mathrm{CI}$ were calculated if any of the matched cells were 0 .

tMatched OR and $95 \% \mathrm{CI}$ were not calculated if any of the unmatched cells were 0.

$95 \% \mathrm{CI}=1.5,19.3, \mathrm{p}$ value $=0.005)$, they were less likely to report use of oral contraceptives $(\mathrm{OR}=0.87,95 \% \mathrm{CI}=0.14,5.27$, $\mathrm{p}$ value $=0.9)$. Cases were less likely than matched controls to consume alcohol $(\mathrm{OR}=0.2,95 \% \mathrm{CI}=0.03$, 0.95 , $\mathrm{p}$ value $=0.03$ ) but were equally likely to smoke cigarettes $(\mathrm{OR}=1.2,95 \% \mathrm{CI}=0.4,3.2, \mathrm{p}$ value $=0.8)$.

GENITOURINARY INFECTIONS

Cases were more likely than matched controls to report a history of genitourinary infections (table 3). Most notably, cases were more likely than controls to have a self reported history of self report of physician diagnosed bacterial vaginosis $(\mathrm{BV})(\mathrm{OR}=22.2,95 \% \mathrm{CI}=2.8,177.2$, $\mathrm{p}$ value $=0.0001)$, vaginal yeast infections $(\mathrm{OR}=5.0,95 \% \mathrm{CI}=1.4,18.0, \mathrm{p}$ value $=0.01)$, and human papillomavirus (HPV) $(\mathrm{OR}=7.1$, $95 \% \mathrm{CI}=0.6,81.2, \mathrm{p}$ value $=0.1)$. There were five cases of pelvic inflammatory disease (PID) in the cases without controls but none among the matched cases ( $p$ value $=0.04)$. Cases on average reported being diagnosed with one more genitourinary infection than matched controls $($ mean $=2.3 v 1.2$, $\mathrm{p}$ value $=0.001)$.
DIET

Diet questionnaires were available for a total of 44 cases (10 matched and 34 unmatched) and 22 controls. The unmatched and matched cases did not differ with respect to dietary intake of oxalate. There were also no differences between matched cases and controls with respect to dietary intake of oxalate, although cases appear to be eating more mean units of high (mean $=57.1 v 53.4, \mathrm{p}$ value $=0.5$ ) and moderate $($ mean $=74.8 \vee 71.7, \mathrm{p}$ value $=0.9$ ) oxalate level foods. Cases also appear to be eating fewer mean units of low (mean $=222.0 v$ 269.6, $\mathrm{p}$ value $=0.4$ ) oxalate foods during the past 4 weeks, although this finding was not statistically significant.

\section{PSYCHOLOGICAL}

Cases were more likely than matched controls to report their health status was fair or poor rather than excellent or good $(\mathrm{OR}=5.7$, $95 \% \mathrm{CI}=1.1,28.7$, p value $=0.02)$, and report being depressed for 2 weeks or more during the past year $(\mathrm{OR}=4.4,95 \% \mathrm{CI}=1.6,12.3, \mathrm{p}$ value $=0.002$ ) (table 4 ). History of past depression was higher among cases, but the results

Table 3 Self reported history of physician diagnosed genitourinary infections among 64 women with vulvar vestibulitis syndrome and 50 matched friend controls

\begin{tabular}{|c|c|c|c|c|c|}
\hline \multirow[b]{2}{*}{ Genitourinary infections } & \multirow{2}{*}{$\begin{array}{l}\text { Unmatched cases } \\
(n=36)\end{array}$} & \multirow{2}{*}{$\begin{array}{l}\text { Matched cases } \\
(n=28)\end{array}$} & \multirow{2}{*}{$\begin{array}{l}\text { Friend controls } \\
(n=50)\end{array}$} & \multirow{2}{*}{$\begin{array}{l}\text { Matched } \\
\chi^{2} p \text { value }\end{array}$} & \multirow{2}{*}{$\begin{array}{l}\text { Matched } \\
\text { OR }(95 \% \text { CI) }\end{array}$} \\
\hline & & & & & \\
\hline Bacterial vaginosis & $10(27.8)$ & $12(42.9)$ & $3(6.1)$ & $0.0001 \ddagger$ & $22.2(2.8,177.2)$ \\
\hline Vaginal yeast infection & $26(72.2)$ & $23(82.1)$ & $25(50.0)$ & 0.01 & $4.9(1.4,18.0)$ \\
\hline Human papillomavirus & $5(13.9)$ & $3(10.7)$ & $1(2.0)$ & 0.1 & $7.1(0.6,81.2)^{\star}$ \\
\hline Urinary tract infection & $22(61.1)$ & $17(60.7)$ & $23(46.0)$ & 0.3 & $1.7(0.7,4.6)$ \\
\hline Pelvic inflammatory disease & $5(13.9)$ & $0(0.0)$ & $0(0.0)$ & $\dagger$ & $\dagger$ \\
\hline Gonorrhoea & $1(2.8)$ & $0(0.0)$ & $0(0.0)$ & $\dagger$ & $\dagger$ \\
\hline Trichomonas & $4(11.1)$ & $1(3.7)$ & $2(4.0)$ & 0.8 & $1.3(0.1,14.5)$ \\
\hline Chlamydia & $1(2.8)$ & $1(3.6)$ & $2(4.0)$ & 0.9 & $1.3(0.1,16.2)$ \\
\hline Endometriosis & $6(16.7)$ & $5(17.9)$ & $2(4.0)$ & 0.02 & $8.6(0.9,78.6)$ \\
\hline \multicolumn{6}{|c|}{ Number of genitourinary infections ever diagnosed } \\
\hline$<2$ & $16(44.4)$ & $8(28.6)$ & $10(41.7)$ & $0.001 \ddagger$ & $7.0(2.0,24.8)$ \\
\hline 2 or more & $20(55.6)$ & $20(71.4)$ & $14(58.3)$ & & \\
\hline
\end{tabular}

$\star$ Logit estimates for the matched OR and $95 \% \mathrm{CI}$ were calculated if any of the matched cells were 0 .

tMatched OR and 95\% CI were not calculated if any of the unmatched cells were 0 .

$\ddagger$ Statistically significant $(\mathrm{p}<0.05)$ with Bonferroni type correction

Note: No cases or controls reported history of syphilis. 
Table 4 Self reported depression characteristics among 64 women with vulvar vestibulitis syndrome and 50 matched friend controls

\begin{tabular}{|c|c|c|c|c|c|}
\hline \multirow[b]{2}{*}{ Depression characteristics } & \multirow{2}{*}{$\begin{array}{l}\begin{array}{l}\text { Unmatched } \\
\text { cases }(n=36)\end{array} \\
\text { No }(\%)\end{array}$} & \multirow{2}{*}{$\begin{array}{l}\begin{array}{l}\text { Matched cases } \\
(n=28)\end{array} \\
\text { No (\%) }\end{array}$} & \multirow{2}{*}{$\begin{array}{l}\text { Friend controls } \\
(n=50)\end{array}$} & \multirow{2}{*}{$\begin{array}{l}\text { Matched } \\
\chi^{2} p \text { value }\end{array}$} & \multirow{2}{*}{$\begin{array}{l}\text { Matched OR } \\
(95 \% \text { CI) }\end{array}$} \\
\hline & & & & & \\
\hline \multicolumn{6}{|l|}{ General health } \\
\hline Fair and poor & $8(22.2)$ & $7(25.0)$ & $2(4.0)$ & \multirow[t]{2}{*}{0.02} & \multirow[t]{2}{*}{$5.7(1.1,28.7)$} \\
\hline Excellent and good & $28(77.8)$ & $21(75.0)$ & $48(96.0)$ & & \\
\hline \multicolumn{6}{|l|}{ Things going your way in the past 4 weeks } \\
\hline Fairly often & $32(88.9)$ & $25(89.3)$ & $47(94.0)$ & \multirow[t]{2}{*}{0.7} & \multirow[t]{2}{*}{$0.7(0.1,3.7)$} \\
\hline Never & $4(11.1)$ & $3(10.7)$ & $3(6.0)$ & & \\
\hline \multicolumn{6}{|c|}{ Not able to overcome difficulties in the past 4 weeks } \\
\hline Fairly often & $20(55.6)$ & $14(50.0)$ & $16(32.0)$ & \multirow[t]{2}{*}{0.1} & \multirow{2}{*}{$2.1(0.8,5.7)$} \\
\hline Never & $16(44.4)$ & $14(50.0)$ & $34(68.0)$ & & \\
\hline \multicolumn{6}{|c|}{ Confident in handling personal problems in the past 4 weeks } \\
\hline Fairly often & $32(88.9)$ & $28(100.0)$ & $49(98.0)$ & \multirow[t]{2}{*}{0.3} & \multirow[t]{2}{*}{$9.0(0.1,831.8)^{\star}$} \\
\hline Never & $4(11.1)$ & $0(0.0)$ & $1(2.0)$ & & \\
\hline \multicolumn{6}{|c|}{ Unable to control important things in the past 4 weeks } \\
\hline Fairly often & $17(47.2)$ & $14(50.0)$ & $17(34.0)$ & \multirow[t]{2}{*}{0.2} & \multirow[t]{2}{*}{$1.8(0.7,4.5)^{\star}$} \\
\hline Never & $19(52.8)$ & $14(50.0)$ & $33(66.0)$ & & \\
\hline Depressed for 2 weeks or more during the past year & $20(55.6)$ & $21(75.0)$ & $17(34.0)$ & 0.002 & $4.4(1.6,12.3)$ \\
\hline Ever depressed for 2 or more years & $11(31.4)$ & $9(32.1)$ & $9(18.0)$ & 0.3 & $1.8(0.7,4.7)$ \\
\hline
\end{tabular}

${ }^{\star}$ Logit estimates for the matched OR and $95 \% \mathrm{CI}$ were calculated if any of the matched cells were 0 .

† Matched OR and $95 \% \mathrm{CI}$ were not calculated if any of the unmatched cells were 0 .

were not statistically significant $(32.1 \%$ v $18.0 \%, \mathrm{p}=0.3$ ).

\section{Discussion}

In this sample of 28 women with VVS and 50 matched friend controls, self reported history of physician diagnosed BV, vaginal yeast infections, and HPV were associated with VVS. Our findings of an association of VVS with $\mathrm{HPV}^{4}{ }^{5-12}$ and vaginal yeast infections ${ }^{3-7}$ are consistent with previous reports; we found no other reports of an association between $\mathrm{BV}$ and VVS.

The high prevalence of self reported BV among cases compared with controls supports the hypothesis that VVS may be a pain syndrome associated with an inflammatory response characterised by the presence of either plasma or mast cells, perhaps similar to reports of increased plasma cells in idiopathic vulvitis $^{2}$ or plasma cell endometritis. ${ }^{25}{ }^{26}$ The inflammatory response of mast cells (secretion of histamine and prostaglandins) is thought to contribute to bladder inflammation and the pain associated with interstitial cystitis, an inflammatory syndrome in the urogenital tract. ${ }^{16}$ Fitzpatrick et al speculated that the tissues from these distinct anatomical sites had common embryological origin and therefore were predisposed to similar pathological responses when challenged. ${ }^{16}$ Chaim et al identified significantly more mast cells in vestibular biopsies from VVS patients than from patients with vulvar relaxation. ${ }^{2}$

Ashman et al speculated that in genetically susceptible women a vaginal candidal infection elicits immunological responses that cross react with host self antigens. ${ }^{27}$ Ashman et al further hypothesised that these responses potentially compromise the normal mechanisms of host resistance and predispose to recurrent vaginal yeast infection and the inflammation caused by the response may contribute to other forms of vaginitis. ${ }^{27}$ The association of VVS with candidal infection also may be explained by the inflammatory response to candidal infection aggravating the pain associated with VVS.
Alternatively, the repeated use of local antimycotic creams could induce a local contact dermatitis or vulvitis by irritant or allergic reaction.

It is possible, and in fact likely, that early symptoms of VVS led cases to be erroneously diagnosed with genitourinary infections including candida vaginitis and BV. Self reported history of physician diagnosis is limited both by patient recall and accuracy of physician diagnosis. Patients with VVS may be more likely to remember the diagnosis of candida vaginitis and $\mathrm{BV}$ than controls. Further, physician diagnosis is often inaccurate in the absence of simple, reliable diagnostic tests and the general, nonspecific nature of vulvovaginal signs and symptoms. ${ }^{28}$ Nevertheless, the prevalence of BV among the cases $(42.9 \%)$ was an order of magnitude higher than that of self report among the general population $(3.1 \%$ ) (B Foxman, unpublished data) and seven times that of matched controls $(6.1 \%)(\mathrm{OR}=22.2,95 \% \mathrm{CI}=2.8,177.2$, $\mathrm{p}$ value $=0.0001)$. When we examined the association of VVS with BV occurring at least 3 years before VVS diagnosis, cases were still 11 times more likely than matched controls to report history of $\mathrm{BV}$ infection $(\mathrm{OR}=11.2$, $95 \% \mathrm{CI}=1.3,98.8, \mathrm{p}$ value $=0.03)$. Although the OR for HPV is large (7.1), the numbers of both cases and controls reported HPV is small and the results do not approach statistical significance. Further, as with BV, cases may be more likely to remember a diagnosis of HPV than controls.

With respect to sexual behaviour, we found no significant differences in sexual activity, either with respect to current or recent past history of engaging in sexual activity, number of partners, or specific types of sexual activity. It is commonly considered that women with VVS suffer greatly when engaging in sexual activity and avoid sexual contact altogether. ${ }^{1}$ Although our data are consistent with the idea that women experience pain during intercourse, it is not, in this population, affecting overall frequency of sexual behaviour although oral sex was less common among cases than 
controls. Cases (and controls) were more likely to report sexual activity in the past 12 months and greater numbers of lifetime partners than a sample of women representative of the United States. $^{29}$

Consistent with previous studies, ${ }^{46713}$ patients with VVS were more likely to report a history of allergies than controls, although the result was not statistically significant. We found cases to be less likely to report use of tampons and more likely to report use of sanitary napkins. This coincides with the notion that vaginal pain is experienced with the insertion of a tampon. The use of over the counter vaginal preparations was significantly higher among cases as was the use of oestrogen. This is probably because cases were prescribed topical oestrogen for VVS symptoms. Cases reported the use of oestrogen more frequently for vaginal symptoms while controls reported the use of oestrogen more for other types of physical symptoms such as "hot flushes" and osteoporosis.

Previous studies have commented on the quality of life and general health associated with a VVS sufferer. ${ }^{318}$ These studies have shown that women with VVS tend to suffer great pain and thus experience a poorer quality of life, depression, and report health status to be quite inferior. We have no measure of quality of life, but cases were more likely to report depression and poorer health status than controls.

With respect to diet, only 10 cases and matched controls completed the dietary questionnaire. However, the results suggest women with VVS might consume more high and medium rather than low oxalate foods, but there was no significant difference in mean oxalate intake. Larger controlled studies are needed to more specifically address this hypothesis.

\section{LIMITATIONS}

Although our study is relatively small, it is one of the larger controlled studies of VVS. The small size limits our ability to detect a more subtle relation between variables, and the lack of statistical significance may as easily reflect the effects of the small sample size as a lack of effect. Our cases were selected from three different practices in Michigan, and are probably not representative of all VVS cases. Cases that supplied names of potential controls were somewhat different from those who did not, but not in important ways with respect to the major new findings of the study: the association with self reported history of bacterial vaginosis. The complicated referral patterns of women with VVS led us to use friend controls because they would reflect the underlying population from which cases were drawn; friend and other matched control groups may be more like cases than randomly selected controls from the population. This was true for sexual behaviour and self reported history of bacterial vaginosis. While clinic controls might have the same complicated referral patterns as women with VVS, it is possible that women attending vaginitis or vulvar clinics would share many risk factors with women with VVS. Although friend controls have some limitations, the biggest being the potential for overmatching, they seemed the most logical choice in this case.

Our case definition of VVS included penetration dyspareunia; however, only $64.3 \%$ of matched cases reported the symptom of pain during vaginal intercourse and $42.1 \%$ reported use of tampons. Because vaginal and urinary symptoms were assessed at time of interview, pain reported at time of diagnosis may not have existed at the time of interview depending on the time between diagnosis and interview. Patients were contacted as soon as possible at all sites. At two sites contact was made within the month following verification of diagnosis but at the third site contact was made up to 6 months after diagnosis. This could explain why some of the women did not experience pain at the time of interview. We did not measure duration of symptoms.

A larger proportion of women than expected did not report pain during intercourse and did report use of tampons. This suggests that women with mild to moderate severity of VVS may be overrepresented in our sample. Although we did not grade the severity of disease we analysed the data by site to control for the effect of differential duration between time at diagnosis and time at interview. There were no statistically significant differences of any of our reported results by site.

\section{Conclusion}

We conducted a case-control study to generate hypotheses pertaining to the pathogenesis of VVS. Cases were equally likely as friend controls to have engaged in vaginal intercourse on a regular basis. They were more likely to report their current health was fair or poor and to report recent and past episodes of depression. We found self reported history of $\mathrm{BV}$, yeast, and HPV to be strongly associated with VVS. Although some of the associations might be explained by an increased chance of diagnosis or recall bias, the association with BV was very strong even if the analysis was limited to $\mathrm{BV}$ diagnoses occurring more than 3 years before the date of VVS diagnosis of the case. The possibility of an infectious origin for VVS should be pursued in larger controlled studies, including both questionnaire and laboratory measures.

This research was supported in part by the Student Award Program grant from the Blue Cross Blue Shield of Michigan Foundation and Drs Foxman, Reid, and Sobel. The authors thank D Reid for access to his patients and his financial support. We are grateful to the following people for participation in data collection: Bonnie Andree, Divya Agrawal, Jean Chung, Susan Pries, and Cheryl Sorg.

Contributors: A V Sarma participated in study design, data collection, data management, and data analyses, and prepared final manuscript and supporting documents; B Foxman participated in study design, data collection, data management, and data analyses, and prepared final manuscript and supporting documents; B Bayirli participated in das collection, data mandocuments; B Bayirli participated in data collection, data management, and data analyses; $\mathrm{H}$ Haefner contributed study patients, and commented on manuscript; J Sobel participated in study design, contributed study patients, and commented on
manuscript.

1 Bergeron S, Binik YM, Khalife S, et al. Vulvar vestibuliti syndrome: a critical review. Clin f Pain 1997;13:27-42.

2 Chaim W, Meriwether C, Gonik B, et al. Vulvar vestibulitis subjects undergoing surgical intervention: a descriptive 
analysis and histopathological correlates. Eur $\mathcal{F}$ Obstet Gynecol Reprod Biol 1996;68:165-8.

3 Meana M, Binik YM, Khalife S, et al. Deconstructing dyspareunia: description, classification and biopsychosocial correlates of a pain disorder [dissertation]. Montreal, Canada: McGill University, 1995.

4 Mann M, Kaufman R, Brown D, et al. Vulvar vestibulitis: significant clinical variables and treatment outcome. Obstet Gynecol 1992;79:122-5.

5 Bazin S, Bouchard C, Brisson J, et al. Vulvar vestibulitis syndrome: an exploratory case-control study. Obstet Gynecol 1994;83:47-50.

6 Pyka R, Wilkinson EJ, Friedrich EG, et al. The histopathology of vulvar vestibulitis syndrome. Int $\mathcal{f}$ Gynecol Pathol ogy of vulvar $1988 ; 7: 249-57$.

7 Marinoff SC, Turner MLC. Hypersensitivity to vaginal candidiasis or treatment vehicles in the pathogenesis of mino

8 Wilkinson EJ, Guerrero E, Daniel R, et al. Vulvar vestibulitis is rarely associated with human papillomavirus infection
types 6, 11, 16 or 18. Int f Gynecol Pathol 1993;12:344-8.

9 Bergeron C, Moyal-Barracco M, Pelisse M, et al. Vulvar vestibulitis: lack of evidence for a human papillomavirus etiology. F Reprod Med 1994;39:936-8.

10 Umpierre SA, Kaufman RH, Adam E, et al. Human papillomavirus DNA in tissue biopsy specimens of vulvar vestibulitis patients treated with interferon. Obstet Gynecol 1991;78:693-5

11 Prayson RA, Stoler MH, Hart WR. Vulvar vestibulitis: as histopathologic study of 36 cases, including human papillomavirus in in-situ hybridization analysis. Am f Surg papillomavirus in in-situ

12 Goetsch MF. Vulvar vestibulitis: prevalence and historic features in a general gynecologic population. Am $\mathcal{F}$ Obstet Gynecol 1991;161:1609-17.

13 Friedrich EG. Vulvar vestibulitis syndrome. 7 Reprod Med 1987;32:110-14

14 Sobel JD, Candidal vulvovaginitis. Clin Obstet Gynecol 1993 36:153-65.

15 McCormack WM. Two urogenital sinus syndromes: interstitial cystitis and focal vulvitis. F Reprod Med 1990:35:873-
16 Fitzpatrick CC, DeLancey JOL, Elkins TE, et al. Vulvar vestibulitis and interstitial cystitis: a disorder of urogenita sinus-derived epithelium? Obstet Gynecol 1993;81:860-2.

17 Peckham BM, Maki DG, Patterson JJ, et al. Focal vulvitis: a characteristic syndrome and cause of dyspareunia. Am $\mathcal{F}$ Obstet Gynecol 1986;154:855-64.

18 Schover LS, Youngs DD, Cannata R. Psychosexual aspects of the evaluation and management vulvar vestibulitis. $A m \mathcal{F}$ Obstet Gynecol 1992;167:630-6.

19 Foster DC, Robinson JC, Davis KM. Urethral pressure variability in women with vulvar vestibulitis syndrome. $A m$ f Obstet Gynecol 1993;169:107-12.

20 Solomons CC, Melmed MH, Heitler SM. Calcium citrate for vulvar vestibulitis: a case report. $\mathcal{F}$ Reprod Med 1991;36: 879-82.

21 Baggish MS, Sze EH, Johnson R. Urinary oxalate excretion and its role in vulvar pain syndrome. Am f Obstet Gynecol 1997; 177:507-11

22 Melmed MH. Treatment of 60 patients with vulvar vestibulitis using low oxalate and calcium citrate diets. International Society for the Study of Vulvar Vaginal Diseases. Iguaza Falls, Argentina, 1995 Sept 25.

23 Hochberg Y, Benjamini Y. More powerful procedures for multiple significance testing. Stat Med 1990;9:811-18.

24 SAS System for Windows [computer software]. Version 6.10. Cary, NC: SAS Institute Inc, 1994.

25 Kamarashev JA, Vassileva SG, Dermatologic diseases of the vulva. Clin Dermatol 1997;15:53-65.

26 Korn AP, Bolan G, Padian N, et al. Plasma cell endometritis in women with symptomatic bacterial vaginosis. Obstet Gynecol 1995;85:387-90.

27 Ashman RB, Ott AK. Autoimmunity as a factor in recurrent vaginal candidosis and the minor vestibular gland synvaginal candidosis and the minor vesti

28 Sobel JD. Vaginitis. N Engl f Med 1997;337:1896-903.

29 Laumann EO, Gagnon JH, Michael RT, et al. The social organization of sexuality: sexual practices in the United States. Chicago: University of Chicago Press; 1994 